\title{
Make Space!: Disruption Analysis of the A380 Operation in Mexico City Airport
}

\author{
Miguel Mujica Mota ${ }^{1}$ Catya Zuniga ${ }^{2}$ Geert Boosten ${ }^{3}$ \\ ${ }^{1,3}$ Aviation Academy, Amsterdam U. of Applied Sciences, The Netherlands, \\ $\{\mathrm{m} . \mathrm{mujica} . \mathrm{mota}, \mathrm{g} \cdot$ boosten $@$ hva.nl \\ ${ }^{2}$ National Aviation U. of Queretaro, Mexico, \{catya.zuniga\}@unaq.edu.mx
}

\begin{abstract}
Recently, the super heavy aircraft A380 started operations between Mexico City and Paris, and it has been announced daily operations in March. In addition, Lufthansa and Emirates are also willing to use the A380 to operate from Frankfurt and Dubai to Mexico, respectively. However, in recent years, Mexico City International Airport has been reporting severe congestion problems and it is a concern whether these problems can be overcome with the current facilities and procedures together with the increasing aircraft demand. In this article, a capacity analysis of the operation performed in the airport is presented using information for a particular high-season day. A model-based approach which allows simulating the daily operation of the A380 is presented. This approach allows incorporating most of the restrictions besides the stochasticity inherent to the system.
\end{abstract}

Keywords: $\quad$ A380, Mexico City Airport, simulation, performance

\section{Introduction}

Recently the A380 started operations between Mexico City and Paris. Some operative problems have been reported and it is a concern whether these problems can be overcome with the current facilities. To make the situation even more challenging, Air France will start daily operations in March or April and also Lufthansa and Emirates are willing to use the A380 to operate from Frankfurt and Dubai respectively (CAPA, 2014). The situation represents a challenge for the airport authorities, first accommodating the non-stopping increasing demand and second the change in the aircraft mix will affect the overall airport performance since the A380 has special requirements (Airbus, 2011). In addition, airport authorities have declared the airport congested in different slots in the last years claiming that the traffic is that high that the airport is not able to cope with the demand reported (AICM, 2015).

For assessing the current situation, we developed a stochastic model of the current airport in which the most relevant technical restrictions are incorporated. In addition, it is also implemented the current operation and routes followed by the aircraft in the ground once it lands.

\section{The importance of Mexico City Airport}

The Mexican air transport system transported in 2015 over 65 million passengers, an increase of $8.5 \%$ compared with the previous year. The total number of operations reached more than 1 million in that year, 748,000 of the total corresponded to national flights and 281,000 to international ones (FlightStats, 2015). This growth has supported the employment of 56.6 million people (direct and indirect jobs) and contributed with over 2.2 trillion USD to global GDP. On the other hand, the domestic sector has been growing as fast as the international one; it increased by $10 \%$ over the previous year transporting 34 million passengers $(60 \%$ of the total) while the international increased a 7\% moving 22 million passengers (SCT, 2015).

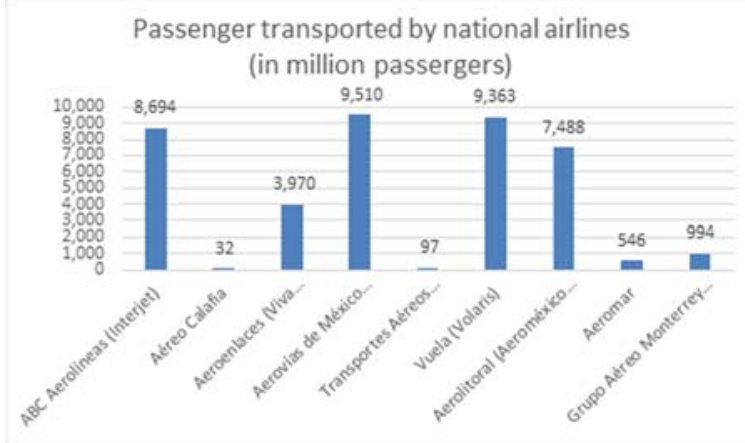

Figure 1. Passengers transported by national airlines in domestic and international routes in 2014.

Figure 1 shows the demand of the 9 regular passenger commercial airlines in México which served domestic and international routes in 2014. It can be noticed that the biggest national airlines in terms of transported passengers are Aeromexico, Volaris, Interjet and Aeromexico-Connect which moved 9.5, 9.3, 8.7 and 7.5 million pax respectively. The rest of passengers (298 000), were transported by 8 charter airlines (SCT, 2015). 
Regarding to low-cost carriers (LCC), Viva Aerobus, which started operations in 2006 is growing quite fast and it is forecasted to be one of the leaders in the low-cost sector. In fact, as it can be seen in Figure 2, the low-cost sector has been growing since 2005, and in 2013 it already accounted with $60 \%$ of the market. Volaris and Interjet together with Viva Aerobus are categorized as the current Mexican low-cost carriers.

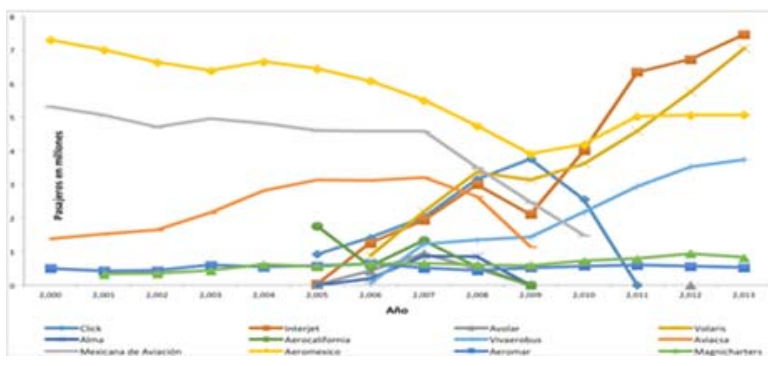

Figure 2. Main development of mexican airlines since 2005.

Table 1 introduces the top 10 domestic routes; from those routes, 47 concentrate $80.2 \%$ of the total passengers; while $80 \%$ of the international travelers use 94 routes and the 10 most frequent are presented in Table 2.

Table 1. Top 10 Domestic Routes in Mexico.

\begin{tabular}{|c|c|c|c|c|c|c|c|}
\hline & \multirow[t]{3}{*}{ Origin } & \multirow[t]{3}{*}{ Destination } & \multirow{2}{*}{\multicolumn{2}{|c|}{\begin{tabular}{|l|}
$\begin{array}{l}\text { Transported } \\
\text { passengers }\end{array}$ \\
(thousands) \\
\end{tabular}}} & \multirow{3}{*}{$\begin{array}{l}\text { Growing } \\
2013 / 2014 \\
\end{array}$} & \multirow{2}{*}{\multicolumn{2}{|c|}{$\begin{array}{l}\text { Origin- } \\
\text { Destination vs } \\
\text { Total \% }\end{array}$}} \\
\hline & & & & & & & \\
\hline & & & 2013 & 2014 & & 2013 & 2014 \\
\hline 1 & Mexico & Cancun & 3,295 & 3,524 & $7.0 \%$ & $10.8 \%$ & $10.7 \%$ \\
\hline 2 & Monterrey & Mexico & 2,460 & 2,736 & $11.2 \%$ & $8.1 \%$ & $8.3 \%$ \\
\hline 3 & Mexico & Guadalajara & 2,278 & 2,379 & $4.4 \%$ & $7.5 \%$ & $7.2 \%$ \\
\hline${ }^{4}$ & Tijuana & Mexico & 1,241 & 1,266 & $2.0 \%$ & $4.1 \%$ & $3.8 \%$ \\
\hline 5 & Mexico & Merida & 1,050 & 1,131 & $7.8 \%$ & $3.4 \%$ & $3.4 \%$ \\
\hline${ }^{6}$ & Tijuana & Guadalajara & 941 & 1,025 & $9.0 \%$ & $3.1 \%$ & $3.1 \%$ \\
\hline 7 & Villahermosa & Mexico & 700 & 776 & $11.0 \%$ & $2.3 \%$ & $2.4 \%$ \\
\hline 8 & Tuxtla Gutierrez & Mexico & 684 & 728 & $6.5 \%$ & $2.2 \%$ & $2.2 \%$ \\
\hline 9 & \begin{tabular}{|l|} 
Monterrey \\
\end{tabular} & Cancun & 673 & 712 & $5.9 \%$ & $2.2 \%$ & $2.2 \%$ \\
\hline 10 & Puerto Vallarta & Mexico & 527 & 606 & $14.9 \%$ & $1.7 \%$ & $1.8 \%$ \\
\hline
\end{tabular}

Table 2. Top 10 International Routes in Mexico.

\begin{tabular}{|c|c|c|c|c|c|c|c|}
\hline & \multirow[t]{3}{*}{ Origin } & \multirow{3}{*}{ Destination } & \multirow{2}{*}{\multicolumn{2}{|c|}{\begin{tabular}{|l|}
$\begin{array}{l}\text { Transported } \\
\text { passengers }\end{array}$ \\
(thousands) \\
\end{tabular}}} & \multirow{3}{*}{$\begin{array}{l}\text { Growing } \\
2013 / 2014\end{array}$} & \multirow{2}{*}{\multicolumn{2}{|c|}{$\begin{array}{l}\text { Origin- } \\
\text { Destination vs } \\
\text { Total \% }\end{array}$}} \\
\hline & & & & & & & \\
\hline & & & 2013 & 2014 & & 2013 & \begin{tabular}{|l|l|}
2014 \\
\end{tabular} \\
\hline 1 & Mexico & Los Angeles & 783 & 813 & $3.8 \%$ & $2.7 \%$ & $2.5 \%$ \\
\hline 2 & New York & Cancun & 731 & 803 & $9.8 \%$ & $2.5 \%$ & $2.5 \%$ \\
\hline 3 & Los Angeles & Guadalajara & 746 & 781 & $4.7 \%$ & $2.5 \%$ & $2.4 \%$ \\
\hline 4 & New York & Mexico & 710 & 760 & $7.2 \%$ & $2.4 \%$ & $2.4 \%$ \\
\hline 5 & Cancun & \begin{tabular}{|l} 
Atlanta \\
\end{tabular} & 661 & 704 & $6.6 \%$ & $2.2 \%$ & $2.2 \%$ \\
\hline 6 & Miami & Mexico & 718 & 694 & $-3.4 \%$ & $2.4 \%$ & $2.2 \%$ \\
\hline 7 & Mexico & Houston & 620 & 693 & $11.7 \%$ & $2.1 \%$ & $2.1 \%$ \\
\hline 8 & Dallas & Cancun & 630 & 678 & $7.7 \%$ & $2.1 \%$ & $2.1 \%$ \\
\hline 9 & Houston & Cancun & 561 & 585 & $4.3 \%$ & $1.9 \%$ & \begin{tabular}{|l|l|}
$1.8 \%$ \\
\end{tabular} \\
\hline 10 & Mexico & Bogota & 469 & 572 & $21.9 \%$ & $1.6 \%$ & \begin{tabular}{|l|l|}
$1.8 \%$ \\
\end{tabular} \\
\hline
\end{tabular}

Mexico counts with 76 airports, 63 of them are international airports and 13 national; in addition there are 1,431 aerodromes registered in the country. This places Mexico as one of the top countries in Latin
America with the major airport network. Figure 3 presents the 10 top airports by passenger traffic within Mexico in 2015. It can be noticed, that Mexico City International airport moves the $35 \%$ the total domestic traffic of the country, followed by four other airports: Monterrey (10\%), Guadalajara (9\%), Cancun (8\%) and Tijuana (6\%), respectively. In the international context, Cancun International airport is a good opponent to Mexico City airport moving 34\% and 33\% of the total, respectively.

It can be said that the busiest airport in the country is Mexico City International Airport (ICAO code: MMMX), located in Mexico city, and which also conforms, since 2003 the pillar of the Metropolitan Airport system, together with Queretaro, Puebla, Toluca and Cuernavaca.

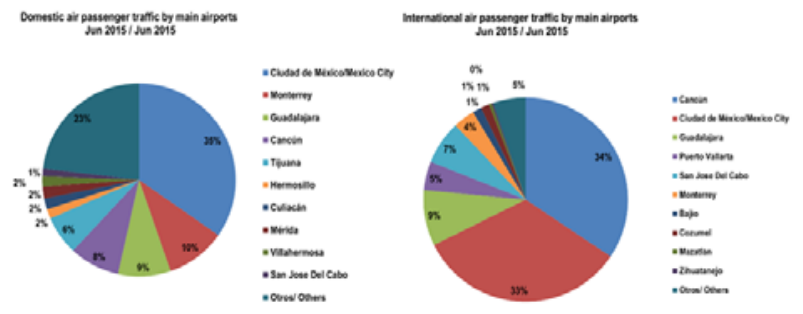

Figure 3. Domestic and International passenger traffic by main airports in Mexico.

Regarding Mexico City Airport, it is considered key for the development of the metropolitan region in Mexico and also for the development of the country. Recently it has been announced the development of the new airport in Mexico City which will have a final capacity of 120 mill pax/yr (Herald On Line, 2014). However the first phase for this airport will not be operative until 2020. In the meantime, Mexico City as a destination is still growing and the country has also gained importance as a tourist and business destination. On the 12th of January 2016, AirFrance started a direct flight from Paris to Mexico City using the mega jumbo A380. At the moment, the flight is only scheduled 3 times a week but it is planned that from March on it will fly on a daily basis (Experience the Skies, 2016). Each flight of the mega Jumbo transports 516 passengers and due to its dimensions and operational requirements some problems have raised in which delays are the most relevant ones.

The flight to and from Paris represents itself a challenge to the airport due to different factors which cause problems to be solved by the airport operator. One problem is that the clearances from the centerline at some taxiways are too narrow for the size of the aircraft which has caused that the aircraft follows a long taxi route to the runway (SENEAMM API, 2015). This operative situation caused that the departure time suffers a delay of 10 to 56 minutes with an average value of 36 minutes (Experience the Skies, 2016). On top of this situation, some years ago the airport authorities 
established a limit of $61 \mathrm{ATM} / \mathrm{HR}$ as the maximum hour capacity for the airport, hence some slots of the airport have been declared congested. Furthermore, Lufthansa and Emirates have stated that they have intentions to start operating with the A380 from Frankfurt and Dubai to Mexico city respectively. For these reasons is critical to have tools and methodologies that allow the study the current and future operation of the airport. Traditional analytical techniques have proven their lack of power for addressing with accuracy the potential problems of a complex system such as the one of Mexico City airport, that is the reason model-based techniques and in particular stochastic modeling appears as the only one with the capability for analyzing with the proper accuracy the current and future operative situations.

Initial simulation-based approaches have been performed by different authors addressing the problems in MMMX and other airports (Herrera, 2012; Bazargan, 2004; Marelli et al, 1998; Soolaki et al, 2012; Mujica, 2015). In this work, the analysis performed using a validated model of the current operation of the Airport of Mexico City it is presented which allows the understanding of the current potential problems and also the ones that will rise once the daily operation of AirFrance takes place.

\section{Model-based Approach}

The developed model is a discrete-event-based model which allows including the stochastic characteristics and level of detail that other analytical approaches would not allow. The level of detail is such, that enables the integration of the technical restrictions, the operative restrictions imposed by the airport authority, the rules in place for the different aircraft such as wake-vortex separation and the taxiway routing for landing and takeoff. The elements that compose the complete model are: the two runways, taxi network, terminal buildings, and parking stands of the two terminals. The model focuses only in the airside of the airport and it does not pay attention to the airspace, flow of passengers or vehicles that perform the services within it, so it is bounded to the airside operation only. Figure 4 illustrates the layout of the model that includes the taxiway network, airport stands and runways and it also depicts the different paths that are followed by the traffic within the airside.

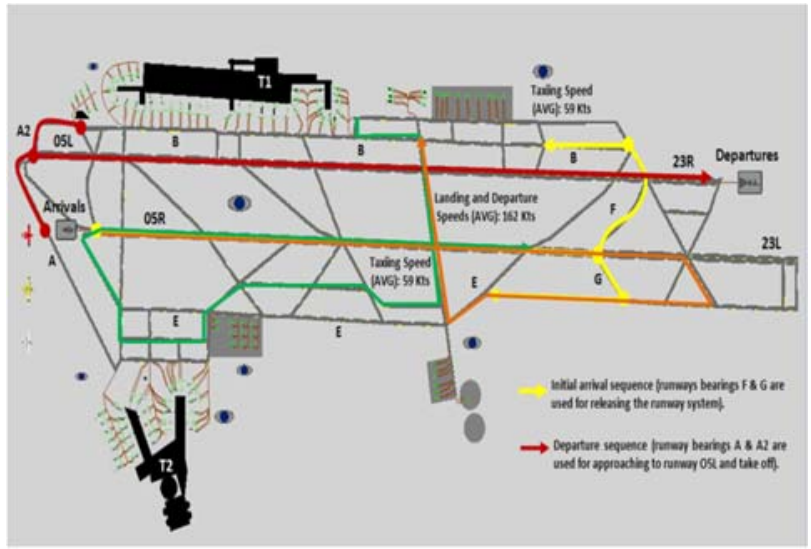

Figure 4. MMMX airport layout with A380.

The yellow path illustrates the normal landing configuration and the red line represents the configuration followed for departing flights. However, the situation of the A380 is slightly different; the A380 follows the orange path and green path for arrival and departure respectively (SCT, 2015).

In order to make the model valid, different characteristics were included in the model besides different assumptions. The most relevant ones are presented in Table 3.

Table 3. Characteristics of the Airside Model.

\begin{tabular}{|c|c|}
\hline Parameter & Value \\
\hline Landing Speed & $\begin{array}{c}\text { Min:150 Knot, Max 175 } \\
\text { Knot, AVG 162 Knot }\end{array}$ \\
\hline Taxiing Speed & $\begin{array}{c}\text { Min: 49 Knot, Max: 68 Knot, } \\
\text { Avg: 59 Knot }\end{array}$ \\
\hline RWY O5L-23R & Length: 3963 m \\
\hline RWY 05 R-23L & Length: 3985 m \\
\hline Number of Stands & T1: 50, T2:46 \\
\hline CenterLine Separation & $310 \mathrm{~m}$ \\
\hline Turnaround Time & $\begin{array}{c}\text { Probability Distributions } \\
\text { depending on the type of AC }\end{array}$ \\
\hline
\end{tabular}

For the traffic demand generation of the model, information from a representative day was collected. The information was considered (FlightStats, 2015), (Flight Radar24, 2015) and then the performance of the model was compared against the real number of air transport movements of the day.

In order to evaluate the impact of the A380,information from the current operation was collected, the type of information that was included in the model is the following:

- Route of Taxi-In and Taxi-Out of the A380

- Speed of the Taxi-In/out of the A380 in the Airport

- Turnaround time

- Current schedule and gate allocation

The operation of the airport has been modified in order to cope with the challenge of giving space for the A380 to operate. Due to the limitations and restriction in the operation, the route of the aircraft is not the standard one but a modified one so that the aircraft is 
able to get to the gates G33 and G34 which were the ones selected for the operation of the A380.

\subsection{Experiments and Analysis}

The results were obtained running first the case without the A380 in order to make possible to establish a base case for comparison. Once the results were obtained with the base case, modifications to the model were made and attention was paid to some performance indicators.

\section{Scenario 1: Base Case}

First the base model was run and the utilization of the gates and the number of operations per hour (ATM/HR) was obtained from the initial replications, Figure 5 illustrates the values of these indicators.

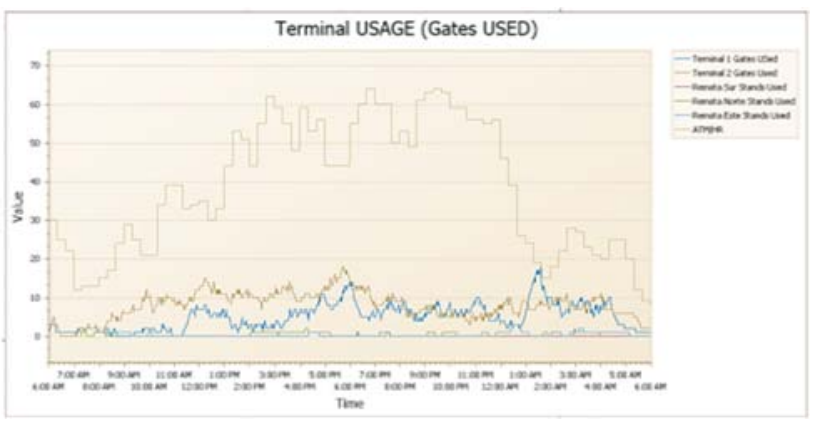

Figure 5. Gate usage and ATM/hr during the day.

Based on the analysis of the base case, it was identified an unbalance in the gates throughout the day. From Figure 5, it can be seen that most of the time the usage of Terminal 2 (brown line) is higher than the usage of Terminal 1 (blue line). It can also be appreciated that, as it has been claimed, during some time of the day, the number of operations has exceeded the declared capacity of the airport (61 Atm/hr), in particular form 1:00 pm until 10:00 pm.

In order to understand the performance capacities of the airport, a statistical analysis of the system was performed and it was evaluated whether the use of the A380 have impacted the operation. For the base case, 30 replications were performed and characteristics of the system were obtained. The most important results are presented in Table 4. From the initial results it can be appreciated that the traffic is apparently unbalanced since the Terminal 2 uses more gates in average than the Terminal 1 during the day. The maximum values represent that at some period of time during the day approximately 21 gates out of the 34 are used. In addition it can also be appreciated that the runway usage is about $69-70 \%$ as it can be seen in the green line of Figure 6.
Table 4. Base Model without A380.

\begin{tabular}{|c|c|c|c|c|}
\hline \multirow[t]{2}{*}{ Facility } & \multirow{2}{*}{$\begin{array}{l}\begin{array}{l}\text { Gate } \\
\text { utilization }\end{array} \\
\text { Max Avg }\end{array}$} & \multicolumn{3}{|c|}{ NO- A380 } \\
\hline & & Min & Max & $\mathrm{HW}$ \\
\hline $\begin{array}{l}\text { Terminal } 1 \\
\text { (36 Gates) }\end{array}$ & 14.4 & 10 & 28 & 1.33 \\
\hline \multirow{2}{*}{$\begin{array}{l}\text { Terminal } 2 \\
\text { (34 Gates) }\end{array}$} & 15.2 & 11 & 21 & 0.88 \\
\hline & AVG & Min & Max & $\mathrm{HW}$ \\
\hline $\begin{array}{l}\text { Ratio } \\
\text { T1Gates/T } \\
2 \text { Gates }\end{array}$ & 0.43 & 0.34 & 0.57 & 0.02 \\
\hline $\begin{array}{l}\text { TWY T1 } \\
\text { queue }\end{array}$ & 5.5 & 4 & 8 & 0.4 \\
\hline $\begin{array}{l}\text { TWY T2, } \\
\text { Queue }\end{array}$ & 3.8 & 2 & 5 & 0.33 \\
\hline
\end{tabular}

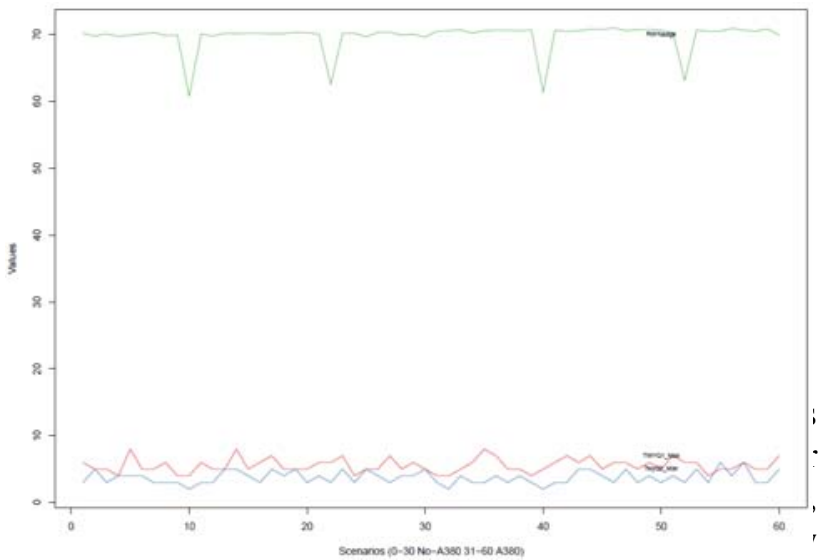

Figure 6. Utilization of runway and gates in the terminals.

This figure suggests that we can identify that the runway is the element of the system that might suffer from the lack of capacity to handle more traffic. Therefore, attention must be paid to that element.

\section{Scenario 2: Disruptive A380}

For the scenario that includes the A380, the same flight schedule was used but the flight of AirFrance at $6: 40 \mathrm{pm}$ was incorporated using the gates G33-G34 and following the published route for the A380 (SCT, 2015). Table 5 shows the results of scenario 2. For this scenario, 30 replications were run for obtaining the performance of the system under the new conditions. 
Table 5. Scenario with A380.

\begin{tabular}{|c|c|c|c|c|}
\hline \multirow[t]{2}{*}{ Facility } & \multirow{2}{*}{$\begin{array}{l}\text { Gate } \\
\text { utilization } \\
\text { Max Avg }\end{array}$} & \multicolumn{3}{|c|}{ With- A380 } \\
\hline & & Min & Max & $\mathrm{HW}$ \\
\hline $\begin{array}{l}\text { Terminal } 1 \\
\text { (36 Gates) }\end{array}$ & 14.16 & 10 & 21 & 0.86 \\
\hline \multirow{2}{*}{$\begin{array}{l}\text { Terminal } 2 \\
\text { (34 Gates) }\end{array}$} & 14.86 & 11 & 21 & 0.93 \\
\hline & AVG & Min & Max & $\mathrm{HW}$ \\
\hline $\begin{array}{l}\text { Ratio } \\
\text { T1Gates/T } \\
2 \text { Gates }\end{array}$ & 0.44 & 0.34 & 0.56 & 0.019 \\
\hline $\begin{array}{l}\text { TWY T1 } \\
\text { queue }\end{array}$ & 5.6 & 4 & 8 & 0.38 \\
\hline $\begin{array}{l}\text { TWY T2, } \\
\text { Queue }\end{array}$ & 3.7 & 2 & 6 & 0.39 \\
\hline
\end{tabular}

From these results, it is apparent that in general terms the utilization rate of both terminals is affected since the maximal utilization and also the average values are negatively modified. However, it can also be appreciated that in some replications of the model and due to the variability the usage is as low as $28 \%$ and $32 \%$ for terminal 1 and terminal 2 respectively.

\section{Impact Analysis}

Once the different values and the data of the operation were obtained, $t$ tests were performed for evaluating if the impact of the operation is statistically significant. These tests were executed over the following indicators with a level of significance of 0.05 :

- Ratio UsageT1/UsageT2

- Effect on Queue of T1

- Effect on Runway usage

- Effect on Queue of T2

- Average T1Gate usage

After running the different tests it was possible only to identify a significant effect over the third performance indicator called Effect on Runway Usage. This indicator deals with the level of congestion of the runway. In our study the runway usage went from $69.5 \%$ to $70.02 \%$. Figure 7 illustrates the effect of the indicator once the A380 appears into scene. The dots with the 0 value correspond to the base case and the ones with the 1 value next to the dots represent the scenario with the A380.

In this figure, the effect of the inclusion of the A380 is evident since the trend is similar but just shifted to a high position in the graph due to the increase in saturation of the capacity.

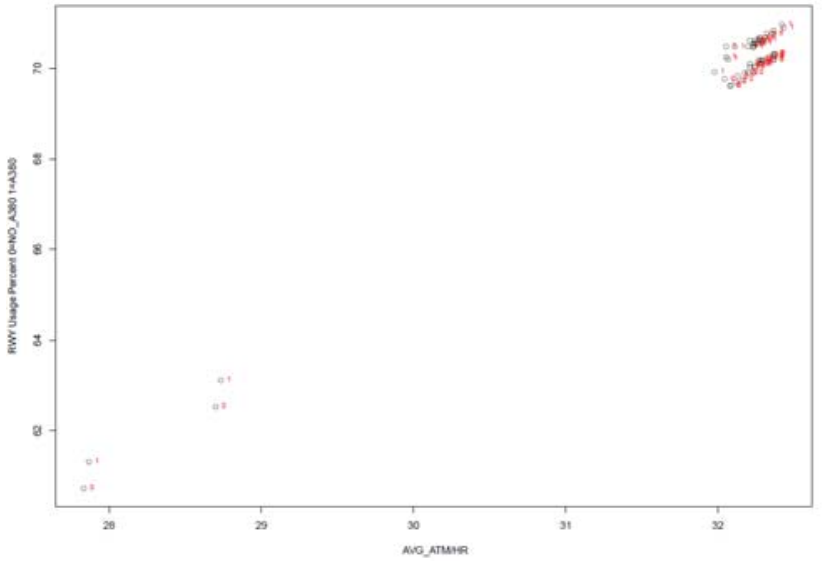

Figure 7. Effect in the RWY of the inclusion of A380.

The next figure also shows the hypothesis test performed for verifying the effect of the A380 in the runway usage. As the reader can appreciate, the shift in the mean is due to the introduction of the A380 as the $p$ value confirms.

Effect on RWY USAGE

t-Test: Paired Two Sample for Means

\begin{tabular}{|l|r|r|}
\hline & Variable 1 & Variable 2 \\
\hline Mean & 69.48701814 & 70.02946 \\
\hline Variance & 4.662065343 & 4.618695 \\
\hline Observations & 30 & 30 \\
\hline Pearson Correlati & 0.9966713 & \\
\hline Hypothesized M & 0 & \\
\hline df & 29 & \\
\hline t Stat & -16.87623209 & \\
\hline$P(T<=t)$ one-tail & $7.74046 \mathrm{E}-17$ & \\
\hline t Critical one-tail & 1.699127027 & \\
\hline$P(T<=t)$ two-tail & $1.54809 \mathrm{E}-16$ & \\
\hline t Critical two-tail & 2.045229642 & \\
\hline
\end{tabular}

Figure 8. Values of the Hypothesis Test.

This result confirms the statement of the airport operator that the runway is the main bottleneck in this system. However, it is also interesting that the system is able to handle this type of aircraft without affecting the operation in the remaining elements of the facility. 


\section{Conclusions}

Airports in the globe are facilities that are very important for the development of a region in any country. Especially international airports have the function as the gateway to economic areas of development.

In the particular case of Mexico, the international airport of Mexico City is a critical infrastructure which works as a catalyst for the development of the region in different aspects that range from tourism to business. In the present article we analyzed through a model-based approach the situation of the operation of the A380 which recently started operations to and from Paris.

We could identify peculiarities of the operation of the airport such as the unbalance of the use of the gates in Terminal 1 and Terminal 2. We run experiments over a couple of scenarios and we could also identify that the operation of the A380 only affected the runway within the system. This result is interesting since it demonstrates that the A380 is not as disruptive as it was initially expected. However, the runway is the most sensitive echelon in the system and the airport should put more focus in the runway management if they want to allow other carriers such as Emirates or Lufthansa fly to Mexico City using A380s.

As a future work, we will study the particular situation of the peak hours of the airport in order to identify the slots that are less sensitive to the operation of a future A380.

\section{Acknowledgements}

The authors would like to thank the Aviation Academy of the University of Applied Sciences for supporting this study and the Dutch Benelux Simulation Society (www.dutchbss.org) and EUROSIM for the dissemination of the findings of this study.

\section{References}

A. Herrera. Simulation Model of Aeronautical Operations at Congested Airports: The case of the Mexico City International Airport. Mexican Institute of Transport, Queretaro, Mexico. Technical publication, 365, 2012.

Airbus. A380 Airplane Characteristics for Airport Planning. Airbus SAS, Blagnac Cedex, France. Technical Report, 326, 2011.

AICM. Statistics and Flight-Schedules, Mexico City International Airport. Available via https://www.aicm.com.mx [accessed September 21, 2015].

CAPA Centre for Aviation. Mexico DGAC: Air France, Lufthansa, Emirates and Turkish Airlines interested in A380 to Mexico City. Available via http://centreforaviation.com/news [accessed June 4, 2014].
Experience the Skies. Airbus A380 Faces Challenges at Mexico City International Airport. Available via http://www.experiencetheskies.com [accessed January 29, 2016].

FlightStats. Benito Juarez International Airport Arrivals/Departures, Flight Stats Inc. Available via https://www.flightstats.com [accessed November 18, 2015].

FlightRadar24. Live Air Traffic. Available via https://www.flightradar24.com/19.43,-99.1/12 [accessed December 15, 2015].

Herald on line. Huge new airport is announced for Mexico's capital. Available via http://www.heraldonline.com/latestnews/article12005174.html [accessed September 2, 2014].

M. Bazargan. Airline operations and Scheduling. Burlington, USA, Ashgate Publishing Company, $1^{\text {st }}$ edition, 205, 2004.

M. Mujica. Check-In allocation improvements through the use of a Simulation-Optimization Approach. Transportation Research Part A, 77: 320-335, 2015.

M. Soolaki, I. Mahdavi, N. Mahdavi-Amiri, R. Hassanzadeh, and A. Aghajani. A new linear programming approach and genetic algorithm for solving airline boarding problem. Applied Mathematical Modelling, 36 (9): 4060-4072, 2012.

S. Marelli, G. Mattocks, and R. Merry. AERO Magazine 1. The Role of Computer Simulation in Reducing Airplane Turn Time. Available via http://www.boeing.com/commercial/aeromagazine [accessed January 6, 2014].

SCT, and SENEAMM. eAPI, 40-MEXICO,7_ADMMMX-2-18 Historical statistics (1992-2014). Secretaria de Comunicaciones y Transportes (SCT), Mexico City, Mexico. Technical report, 2015. 